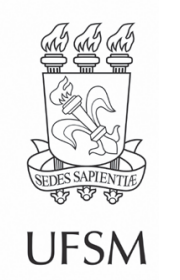

\title{
Artigos
}

\section{Rendimento gravimétrico da carbonização e caracterização qualitativa do carvão vegetal em clones de híbridos de Corymbia spp para uso industrial}

\author{
Carbonization gravimetric yield and qualitative characterization of \\ charcoal from hybrid Corymbia spp clones for industrial use
}

\author{
Breno Assis Loureiro ${ }^{\circledR}$, Maíra Reis de Assis $" \oplus^{\bullet}$ \\ Isabel Cristina Nogueira Alves de Melo ${ }^{\circledR}{ }^{\circ}$, \\ Ana Flávia Fernandes de Oliveira '๑ , Paulo Fernando' Trugilho ${ }^{1 \odot}$ \\ ' Universidade Federal de Lavras, Lavras, MG, Brasil \\ " Pesquisadora Autônoma, Sete Lagoas, MG, Brasil
}

\section{RESUMO}

Na presente pesquisa, objetivou-se avaliar os rendimentos gravimétricos da carbonização e as características qualitativas do carvão vegetal de clones de híbridos obtidos dos cruzamentos de espécies de Corymbia, e identificar os mais adequados para uso siderúrgico. Seis clones, aos 6 anos e 5 meses de idade, foram utilizados na pesquisa e amostradas cinco árvores de cada material genético. As carbonizações laboratoriais foram realizadas à temperatura final de $450^{\circ} \mathrm{C}$, taxa de aquecimento de $100^{\circ} \mathrm{C} . \mathrm{h}^{-1}$ e tempo de residência de 30 minutos. Os rendimentos gravimétricos da carbonização foram determinados em relação à madeira seca. O carvão produzido foi qualificado, considerando-se a análise química imediata, poder calorífico superior, densidade energética, consumo específico de madeira e a eficiência energética. Na avaliação do experimento, foi utilizado o delineamento inteiramente casualizado com cinco repetições (árvores). A análise multivariada de componentes principais foi empregada para obter a variância dos vetores normalizados, considerando as características avaliadas nos carvões. Os resultados obtidos indicaram o elevado potencial para a utilização dos materiais genéticos de Corymbia, para fins energéticos, sobretudo para a produção de carvão vegetal siderúrgico. O clone 1 foi o destaque para a produção de carvão vegetal e lenha, pois apresenta maiores densidades aparentes e energéticas, maior teor e rendimento em carbono fixo, além de possuir menor consumo específico de madeira por tonelada de carvão vegetal produzido. Os clones 2 e 4 foram os que mais se distinguiram dos demais, respectivamente, em decorrência de seu maior teor de cinzas e por apresentar maior consumo específico de madeira na produção de carvão. O uso de clones híbridos de Corymbia, para a produção de carvão vegetal, pode ser uma boa alternativa, em razão de seu rápido crescimento e qualidades semelhantes de madeira e carvão vegetal a outras espécies que já são usadas para a finalidade energética.

Palavras-chave: Energia de biomassa; Carbonização; Qualidade 


\begin{abstract}
This research aimed to evaluate the carbonization gravimetric yields and qualitative characteristics of the charcoal of hybrid clones obtained from the crossings of Corymbia species and to identify the most suitable for the steel industry. We used six clones, at six years and five months of age, sampling five trees of each genetic material. The laboratory carbonizations consisted of a final temperature of $450^{\circ} \mathrm{C}$, a heating rate of $100^{\circ} \mathrm{C} . \mathrm{h}^{-1}$, and a residence time of 30 minutes. We determined the carbonization gravimetric yields when compared to dry wood. The charcoal produced was qualified considering the proximate chemical analysis, superior calorific value, energy density, specific wood consumption, and energy efficiency. We organized the experiment in a completely randomized design with five replicates (trees). The multivariate principal component analysis determined the variance of the normalized vectors, considering the charcoal characteristics evaluated. The results indicated a high potential for the use of Corymbia genetic materials for energy purposes, especially for producing charcoal for the steel industry. Clone 1 was prominent for producing charcoal and firewood, given its higher apparent and energetic densities, fixed carbon content and yield, and lower specific wood consumption per ton of charcoal produced. Clones 2 and 4 most distinguished themselves from the others due to higher ash content and higher specific wood consumption, respectively. The use of Corymbia hybrid clones for producing charcoal may be a good alternative due to its rapid growth and wood and charcoal characteristics similar to those of other species that are already used for energy purposes.
\end{abstract}

Keywords: Biomass energy; Carbonization; Quality

\title{
1 INTRODUÇÃO
}

O Brasil é um dos maiores produtores e consumidores de carvão vegetal do mundo com potencial para aumentar a produção. Esse fato se deve a siderurgia brasileira ter, nesse produto, uma notável matéria-prima, em razão do seu comportamento como combustível e redutor, por ser renovável e ambientalmente correto quando oriundo de florestas plantadas. Uma estratégia para alcançar maior eficiência é cultivar árvores de rápido crescimento, associado à redução do ciclo de corte, em que atingem, rapidamente, o tamanho econômico ideal. Os materiais genéticos de crescimento rápido precisam ser avaliados quanto à qualidade da madeira e à produção do carvão vegetal, além disso, vale salientar que as estratégias de geração de híbridos melhoraram esses parâmetros e produziram clones superiores.

A qualidade do carvão vegetal pode ser avaliada por análise química imediata, rendimentos gravimétricos e densidade relativa aparente, entre outras. A análise 
imediata determina a composição do carvão vegetal depois de queimado como umidade, matéria volátil, carbono fixo e cinzas. Carbono fixo é a porção de carvão que permanece como resíduo, após a remoção dos materiais voláteis, umidade e minerais. Para a operação dos altos fornos, é preferível teor superior a 75\% (BRUZUAL, 2015). As cinzas representam a fração inorgânica que permanece, após a combustão completa. Para uso na siderurgia, o carvão deve ter no máximo 1,5\% desse material, pois podem afetar a queima e dificultar a gaseificação, em razão das interações entre a fração inorgânica e a matéria combustível (ROUSSET et al., 2011).

A dificuldade no uso do carvão vegetal é decorrente da alta variabilidade em sua qualidade, que está associada à grande influência da madeira que Ihe deu origem e do sistema de produção. Essa variabilidade gera excesso de desperdício do material, pois prejudica a operação dos altos fornos siderúrgicos (PEREIRA et al., 2013). Para a produção de carvão vegetal, por exemplo, preferem-se madeiras com maiores densidades e maiores teores de lignina, tais características devem ser consideradas e associadas às de crescimento volumétrico, para a seleção de materiais genéticos superiores (CASTRO et al., 2013). Essas propriedades, por sua vez, são influenciadas por diferentes fatores, como: o genótipo $(G)$, ambiente $(A)$ e interação $(G \times A)$, além da idade (TRUGILHO et al., 2015). Por essas razões, pesquisas têm sido realizadas na tentativa de encontrar clones mais promissores para produção de carvão vegetal (NEVES et al., 2011; PROTÁSIO et al., 2015; TRUGILHO et al., 2015; LOUREIRO et al., 2019).

A maior parte dos estudos tem sido realizada com madeira das espécies do gênero Eucalyptus e de seus clones que, na atualidade, possuem baixa densidade básica. O desafio é encontrar materiais genéticos de elevada densidade básica e que possam produzir carvão vegetal de alta qualidade. Nesse sentido, as espécies do gênero Corymbia vêm se destacando para produção de carvão vegetal. O gênero vem se destacando pelo alto incremento volumétrico e densidade básica da madeira desejáveis. Além disso, podem ser tolerantes a diversas pragas e doenças, bem como 
a estressores ambientais, como o vento, frio, geada e seca (LEE et al., 2009). Híbridos interespecíficos de Corymbia apresentam alta produção de biomassa, em decorrência da associação de alta densidade básica e crescimento volumétrico, do que em plantios de sementes produzidas por polinização aberta. A geração de híbridos do cruzamento entre as espécies de Corymbia citriodora e Corymbia torelliana aumenta a chance das progênies resultantes serem mais vigorosas do que os progenitores (LEE et al., 2009; REIS et al., 2014).

O crescente aumento na contribuição da base de conhecimentos na área de aplicação energética da madeira é, cada vez mais, indispensável, estimulando o interesse de pesquisadores e técnicos nas áreas vinculadas à atividade florestal no Brasil. Tendo em vista que as questões associadas à silvicultura já estão, de certa forma, devidamente controladas, deve evoluir e incluir a avaliação da capacidade máxima de produção de carvão vegetal desses novos materiais genéticos obtidos dos referidos cruzamentos genéticos.

Dentro desse contexto, na presente pesquisa, objetivou-se avaliar os rendimentos gravimétricos da carbonização e as características qualitativas do carvão vegetal de clones de híbridos obtidos dos cruzamentos de espécies de Corymbia, e identificar os mais adequados para uso siderúrgico.

\section{MATERIAL E MÉTODOS}

O estudo foi realizado com amostras de madeira de três híbridos do cruzamento Corymbia citriodora (Hook.) K.D. Hill \& L.A.S Johnson x Corymbia torelliana (F. Muell.) K.D. Hill \& L.A.S Johnson e três do Corymbia torelliana (F. Muell.) K.D. Hill \& L.A.S Johnson x Corymbia citriodora (Hook.) K.D. Hill \& L.A.S Johnson. Cinco árvores, por material genético, foram coletadas em teste clonalda empresa ArcelorMittal Bioflorestas instalado no município de Dionísio, Minas Gerais. O espaçamento foi de 3,0 m x 2,5 m e, na ocasião da colheita, todas as árvores estavam com 6 anos e 5 meses de idade.

Após o abate das árvores amostras, cinco discos de madeira, com aproximadamente 
2,5 cm de espessura, foram retirados nas posições longitudinais de 0\%, 25\%, 50\%, 75\% e $100 \%$ da altura comercial de cada árvore, definida até a circunferência de 9,4 cm. Os discos foram subdivididos em quatro cunhas, passando pela medula, em que duas opostas foram destinadas a carbonização da madeira. As cunhas foram previamente secas em estufa com circulação forçada de ar à temperatura de $103^{\circ} \mathrm{C}$ até atingirem a massa constante. A carbonização foi em forno elétrico de laboratório, utilizando as seguintes condições: temperatura inicial de $100^{\circ} \mathrm{C}$, temperatura máxima de $450^{\circ} \mathrm{C}$, taxa de aquecimento de $100^{\circ} \mathrm{C} \mathrm{h}^{-1}$, tempo de residência de 30 minutos e tempo total de 4 horas. Finalizado o processo, o forno foi desligado, para o esfriamento e retirada dos carvões para o cálculo dos rendimentos gravimétricos e análises subsequentes.

Os rendimentos gravimétricos em carvão vegetal (RGC), em líquido pirolenhoso $(R L P)$, gases não condensáveis (RGNC) e em carbono fixo (RCF) foram obtidos em relação à massa seca de madeira. Amostras representativas dos carvões produzidos foram separadas, moídas e classificadas nas peneiras de 40 (0,42 mm) e 60 mesh $(0,25 \mathrm{~mm})$. Posteriormente, foi realizada a análise química imediata, de acordo com os procedimentos da norma D1762-84 (AMERICAN SOCIETY FOR TESTING MATERIALS, 2007).

A densidade relativa aparente do carvão vegetal foi obtida, utilizando-se o método hidrostático, mesmo procedimento da norma NBR 11941 (ASSOCIAÇÃO BRASILEIRA DE NORMAS TÉCNICAS, 2003). O poder calorífico superior (PCS) do carvão foi determinado de acordo com a norma E711-87 (AMERICAN SOCIETY FOR TESTING MATERIALS, 2004).

As estimativas de eficiência energética da carbonização (EE), consumo específico de madeira (CE) e densidade energética (DE) foram determinadas conforme as Equações (1), (2) e (3).

$\mathrm{EE}=\mathrm{RGC} .(\mathrm{PCS}$ carvão /PCS madeira)

$\mathrm{CE}=1 /(\mathrm{DB} .(\mathrm{RGC} / 100))$

DE $=$ PCScarvão .DRA

Em que: $\mathrm{RGC}$ = rendimento gravimétrico de carvão vegetal (\%); PCS carvão e PCS madeira = poder calorífico do carvão e madeira (cal.g-1 $)$; DB = densidade básica da madeira (t.m ${ }^{-3}$ ); DRA = densidade relativa aparente do carvão vegetal $\left(\mathrm{g} \cdot \mathrm{cm}^{-3}\right)$. 
Na avaliação do experimento, foi considerado o delineamento inteiramente casualizado (DIC) com seis tratamentos (clones) e cinco repetições (árvores-amostras). Foi realizada a análise de variância (ANAVA) e aplicad o o teste Scott-Knott ao nível de 5\% de probabilidade. A escolha pelo teste Scott-Knotté por ele ser um teste de agrupamento univariado, ou seja, agrupa similaridades, além de facilitar a discussão dos resultados. A análise multivariada de componentes principais (ACP) foi utilizada, a fim de explicar a estrutura de variância do vetor aleatório composto pelas características avaliadas no carvão dos materiais genéticos estudados, em que se consideraram as médias de cada variável por árvore. Para a análise das componentes principais, utilizou-se a matriz de correlação e as combinações lineares estabelecidas foram interpretadas, por meio dos autovetores normalizados e das correlações entre as variáveis originais e as componentes principais. As análises estatísticas foram realizadas, utilizando-se o software estatístico R versão 3.3.3 (R CORE TEAM, 2016).

\section{RESULTADOS E DISCUSSÃO}

O efeito de clone foi não significativo para o rendimento gravimétrico de carvão vegetal dos híbridos de Corymbia, o coeficiente de variação foi baixo, indicando a boa coleta dos dados e a eficiência do delineamento estatístico utilizado, conforme apresentado na Tabela 1.

Valores superiores a 30\% são encontrados na literatura (ZANUNCIO et al., 2014; LOUREIRO et al., 2019) para o rendimento em carvão, resultados que são desejados pelas indústrias, constatando o potencial dos híbridos estudados para a finalidade energética. Os resultados de rendimentos gravimétricos em carvão foram maiores aos encontrados na literatura, para diferentes clones de Eucalyptus em idades semelhantes (ASSIS et al., 2012; PROTÁSIO et al., 2014; SOARES et al., 2014).

Segundo Neves et al. (2011) e Protásio et al. (2011), considerados os aspectos produtivos, é desejável obter elevado rendimento gravimétrico em carvão vegetal, em razão do maior aproveitamento da madeira nos fornos de carbonização e, 
consequentemente, maior produção de energia e menores rendimentos em líquido e em gases não condensáveis, pois esses são subprodutos do processo de pirólise.

Tabela 1 - Valores médios dos rendimentos gravimétricos da carbonização

\begin{tabular}{|c|c|c|c|c|c|}
\hline Clones & Cruzamento & RGC (\%) & RLP (\%) & RGNC (\%) & RCF (\%) \\
\hline \multirow{2}{*}{1} & Corymbia citriodora $\mathrm{x}$ & $33,01(0,23)$ & $41,98^{(2,36)}$ & $25,01(2,27)$ & $26,07^{(0,13)}$ \\
\hline & Corymbia torelliana & $a$ & a & $b$ & a \\
\hline \multirow{2}{*}{2} & Corymbia citriodora $\mathrm{x}$ & $32,52(0,58)$ & $46,57^{(1,06)}$ & $20,92^{(1,46)}$ & $25,09(0,60)$ \\
\hline & Corymbia torelliana & $a$ & $b$ & a & $b$ \\
\hline \multirow{2}{*}{3} & Corymbia citriodora $\mathrm{x}$ & $33,04^{(0,54)}$ & $46,88^{(1,42)}$ & $20,08^{(1,20)}$ & $25,55^{(0,45)}$ \\
\hline & Corymbia torelliana & $a$ & $b$ & $a$ & $b$ \\
\hline \multirow{2}{*}{4} & Corymbia torelliana $\mathrm{x}$ & $34,11(0,87)$ & $44,49(2,23)$ & $21,40^{(2,84)}$ & $24,87^{(0,42)}$ \\
\hline & Corymbia citriodora & a & a & a & $b$ \\
\hline \multirow{2}{*}{5} & Corymbia torelliana $\mathrm{x}$ & $33,35^{(0,48)}$ & $43,30^{(1,81)}$ & $23,35^{(1,56)}$ & $26,24^{(0,58)}$ \\
\hline & Corymbia citriodora & a & a & $b$ & a \\
\hline \multirow{6}{*}{6} & Corymbia torelliana $\mathrm{x}$ & $32,99(0,66)$ & $43,00(1,92)$ & $24,01(2,11)$ & $25,45^{(0,61)}$ \\
\hline & Corymbia citriodora & a & a & $\mathrm{b}$ & $\mathrm{b}$ \\
\hline & $\begin{array}{c}\text { Média Corymbia citriodora } \mathrm{x} \\
\text { Corymbia torelliana }\end{array}$ & 32,86 & 45,14 & 22,00 & 25,57 \\
\hline & $\begin{array}{l}\text { Média Corymbia torelliana } \mathrm{x} \\
\text { Corymbia citriodora }\end{array}$ & 33,48 & 43,60 & 22,92 & 25,52 \\
\hline & Média Geral & 33,17 & 44,37 & 22,46 & 25,54 \\
\hline & CVe (\%) & 2,46 & 5,59 & 11,55 & 2,59 \\
\hline
\end{tabular}

Fonte: Autores (2019)

Em que: RGC, RLP, RGNC e RCF = rendimentos gravimétricos em carvão vegetal, em líquido pirolenhoso, em gases não condensáveis e em carbono fixo; CVe = coeficiente de variação experimental. Valores médios seguidos da mesma letra não diferem entre si, a $5 \%$ de probabilidade, pelo teste Scott-Knott.

Na Tabela 1, observou-se que o efeito significativo de clone, para o rendimento em líquido pirolenhoso (RLP), gases não condensáveis (RGNC) e em carbono fixo (RCF). Os clones 1, 5 e 6 apresentaram os maiores e menores valores de RGNC e RLP, respectivamente. Esse resultado é considerado como desvantagem e atribuído às diferenças na composição química da madeira desses materiais (COUTO et al., 2013; PROTÁSIO et al., 2013). Contudo, visando a aumentar a eficiência energética da conversão de madeira em carvão vegetal e reduzir a poluição do ar, pode-se optar pela queima desses gases, utilizando-se, por exemplo,o sistema forno-fornalha e, 
consequentemente, obter energia para o próprio processo de pirólise (CARDOSO et al., 2010; OLIVEIRA et al., 2013).

Quanto ao RCF, que expressa a quantidade de carbono presente na madeira e que ficou retida no carvão vegetal, foi observado que os clones 1 e 5 apresentaram os maiores valores entre os cruzamentos, diferindo, estatisticamente, dos demais. 0 valor médio observado neste trabalho assemelha-se ao encontrado por Neves et al. (2011), Assis et al. (2012) e Protásio et al. (2015) para o carvão vegetal de Eucalyptus. Esse resultado mostra a influência da matéria-prima nessa variável, pois o RCF é obtido pela multiplicação do teor de carbono fixo com o rendimento gravimétrico em carvão vegetal e sabe-se que essas duas últimas variáveis apresentam correlação negativa (PROTÁSIO et al., 2011). Logo, no cálculo do rendimento em carbono fixo é mantida uma proporcionalidade, em que o rendimento em carvão tende a reduzir e o teor de carbono fixo a aumentar com a temperatura final de carbonização, além disso, o teor de carbono elementar na madeira tende a ser semelhante para diferentes espécies.

A análise de variância mostrou que o efeito de clone foi significativo a 95\% de probabilidade somente para o teor de carbono fixo e cinzas (Tabela 2).

Para a utilização energética do carvão vegetal deve se analisar o teor de carbono fixo, de materiais voláteis e cinzas, pois essas variáveis apresentam significativas correlações com o poder calorífico do carvão. Quanto maior o teor de carbono fixo, e menores os teores de materiais voláteis e cinzas, maior será o poder calorífico superior do combustível (PAULA et al., 2011).

O teor de cinzas apresentou maior coeficiente de variação (Tabela 2), isso pode ser elucidado em razão do menor valor numérico das cinzas em relação ao material volátil e carbono fixo (ASSIS et al., 2012). O clone 4 apresentou o maior teor de cinzas e diferiu, estatisticamente, dos demais. Segundo Rousset et al. (2011), o teor de cinzas inferior a 1,5\% é mais apropriado ao uso siderúrgico, para evitar a redução do poder calorífico do carvão e a contaminação do ferro gusa, além de poder contribuir com o desgaste estrutural no altoforno. Nesse contexto, apenas os clones 3 e 6 apresentaram valores inferiores de cinzas e aptos ao uso industrial. 
Os clones 4 e 5 apresentaram os menores teores de carbono fixo e diferiram, estatisticamente, dos demais. O porcentual de carbono fixo refere-se à fração do carbono no carvão que queima no estado sólido. Assim, são preferidos os combustíveis com elevados teores de carbono fixo para uso siderúrgico, em decorrência da estabilidade térmica e o maior valor calórico (BRAND; MUÑIZ, 2010; NEVES et al., 2011; PROTÁSIO et al., 2011). Contudo, mesmo havendo efeito de clone para o teor de carbono fixo, o mesmo não ocorreu para o poder calorífico superior. Esse fato sugere a baixa influência da madeira nas características químicas e energéticas do carvão vegetal e pode ser explicado pela temperatura final de carbonização ter sido constante (PROTÁSIO et al., 2014).

Tabela 2 - Valores médios da composição química imediata e poder calorífico superior do carvão produzido

\begin{tabular}{|c|c|c|c|c|c|}
\hline Clones & Cruzamento & MV (\%) & CF (\%) & CZ (\%) & PCS $\left(M J k^{-1}\right)^{n s}$ \\
\hline 1 & $\begin{array}{l}\text { Corymbia citriodora } \mathrm{x} \\
\text { Corymbia torelliana }\end{array}$ & $\begin{array}{c}22,68^{(0,71)} \\
a\end{array}$ & $\begin{array}{c}75,62^{(0,63)} \\
a\end{array}$ & $1,67^{(0,17)} \mathrm{a}$ & $31,00^{(0,41)} \mathrm{a}$ \\
\hline 2 & $\begin{array}{l}\text { Corymbia citriodora } \mathrm{x} \\
\text { Corymbia torelliana }\end{array}$ & $\begin{array}{c}24,41^{(0,64)} \\
a\end{array}$ & $\begin{array}{c}74,03^{(0,90)} \\
a\end{array}$ & $1,56^{(0,27)} \mathrm{a}$ & $30,97^{(0,25)} \mathrm{a}$ \\
\hline 3 & $\begin{array}{l}\text { Corymbia citriodora } \mathrm{x} \\
\text { Corymbia torelliana }\end{array}$ & $\begin{array}{c}23,99^{(0,60)} \\
a\end{array}$ & $\begin{array}{c}74,70^{(0,61)} \\
a\end{array}$ & $1,31^{(0,07)} \mathrm{a}$ & $31,10^{(0,34)} \mathrm{a}$ \\
\hline 4 & $\begin{array}{l}\text { Corymbia torelliana } \mathrm{x} \\
\text { Corymbia citriodora }\end{array}$ & $\begin{array}{c}25,11^{(1,99)} \\
a\end{array}$ & $\begin{array}{c}72,77^{(1,98)} \\
b\end{array}$ & $2,12^{(0,27)} \mathrm{b}$ & $30,46^{(0,53)} \mathrm{a}$ \\
\hline 5 & $\begin{array}{l}\text { Corymbia torelliana } \mathrm{x} \\
\text { Corymbia citriodora }\end{array}$ & $\begin{array}{c}26,93^{(2,53)} \\
a\end{array}$ & $\begin{array}{c}71,51^{(2,48)} \\
\text { b }\end{array}$ & $1,55^{(0,06)} \mathrm{a}$ & $30,98^{(0,43)} \mathrm{a}$ \\
\hline \multirow[t]{5}{*}{6} & $\begin{array}{l}\text { Corymbia torelliana } \mathrm{x} \\
\text { Corymbia citriodora }\end{array}$ & $\begin{array}{c}24,34^{(0,46)} \\
a\end{array}$ & $\begin{array}{c}74,19^{(0,53)} \\
a\end{array}$ & $1,47^{(0,11)} \mathrm{a}$ & $31,18^{(0,13)} \mathrm{a}$ \\
\hline & $\begin{array}{c}\text { Média Corymbia citriodora } \mathrm{x} \\
\text { Corymbia torelliana }\end{array}$ & 23,69 & 74,78 & 1,51 & 7409 \\
\hline & $\begin{array}{c}\text { Média Corymbia torelliana } \mathrm{x} \\
\text { Corymbia citriodora }\end{array}$ & 25,46 & 72,82 & 1,71 & 7373 \\
\hline & Média Geral & 24,58 & 73,80 & 1,61 & 7391 \\
\hline & CVe (\%) & 7,73 & 2,63 & 15,53 & 1,54 \\
\hline
\end{tabular}

Fonte: Autores (2019)

Em que: $\mathrm{MV}, \mathrm{CF}$ e CZ = teores de materiais voláteis, carbono fixo e cinzas; $\mathrm{PCS}$ = poder calorífico superior; $\mathrm{CVe}=$ coeficiente de variação experimental. Valores médios seguidos da mesma letra não diferem entre si, a 5\% de probabilidade, pelo teste Scott-Knott. 
De modo geral, são desejáveis carvões com altos teores de carbono fixo e baixos teores de materiais voláteis e cinzas, pois tendem a queimar mais lentamente, significando maior tempo de residência no alto forno para a queima total, o que reflete na melhoria do seu consumo específico.

Na siderurgia, maiores poderes caloríficos refletem em menor consumo do redutor (carbono) para uma mesma produtividade e garante, para um mesmo volume de carvão, maior quantidade de calor desprendida durante a combustão (NEVES et al., 2011).

Os valores médios de densidade relativa aparente do carvão dos clones híbridos estão mostrados na Figura 1. Os resultados são considerados satisfatórios e potenciais para utilizações energéticas, especialmente na siderurgia, que necessita de carvão mais denso possível, pois, para um mesmo volume, a densidade está relacionada ao volume ocupado pelo biotermoredutor no alto forno. Sabe-se que quanto maior a densidade aparente do carvão, maior será a sua resistência mecânica, maiores serão os estoques energéticos e de carbono fixo (PROTÁSIO et al., 2013; MOUTINHO et al., 2017), interferindo, positivamente, no consumo específico do reator.

A densidade relativa aparente encontrada no presente estudo (Figura 1) está abaixo dos valores encontrados para o carvão produzido com madeira de híbridos de Corymbia, conforme encontrados e discutidos por Zanuncio et al. (2014) e Moutinho et al. (2017). As diferenças observadas na densidade aparente do carvão são reflexos das diferenças na densidade básica da madeira dos clones híbridos, pois existe correlação altamente positiva entre essas características (VALE et al., 2010).

Assis et al. (2012) mencionaram que a densidade aparente foi a característica mais relevante para a diferenciação de amostras de carvão vegetal produzidas, na mesma condição de pirólise, reforçando a importância dessa variável na avaliação do carvão vegetal, para uso siderúrgico ou energético.

A densidade relativa aparente e o poder calorífico superior influenciam a densidade energética. Na Figura 1, observa-se que, como não houve diferença 
estatística significativa no poder calorífico dos carvões dos clones avaliados de Corymbia, a densidade energética apresentou o mesmo comportamento da densidade relativa aparente, em que os clones 2 e 4 apresentaram os menores valores entre os demais. Embora a densidade energética não possa ser usada para prever, diretamente, o rendimento de carvão, pode ser um bom parâmetro a considerar, em decorrência da correlação positiva com a densidade relativa aparente (LOUREIRO et al., 2019).

Figura 1 - Valores médios para densidade relativa aparente e densidade energética do carvão vegetal. Médias seguidas pela mesma letra não diferem entre si a 5\% de significância pelo teste Scott-Knott entre os materiais genéticos, para a mesma propriedade

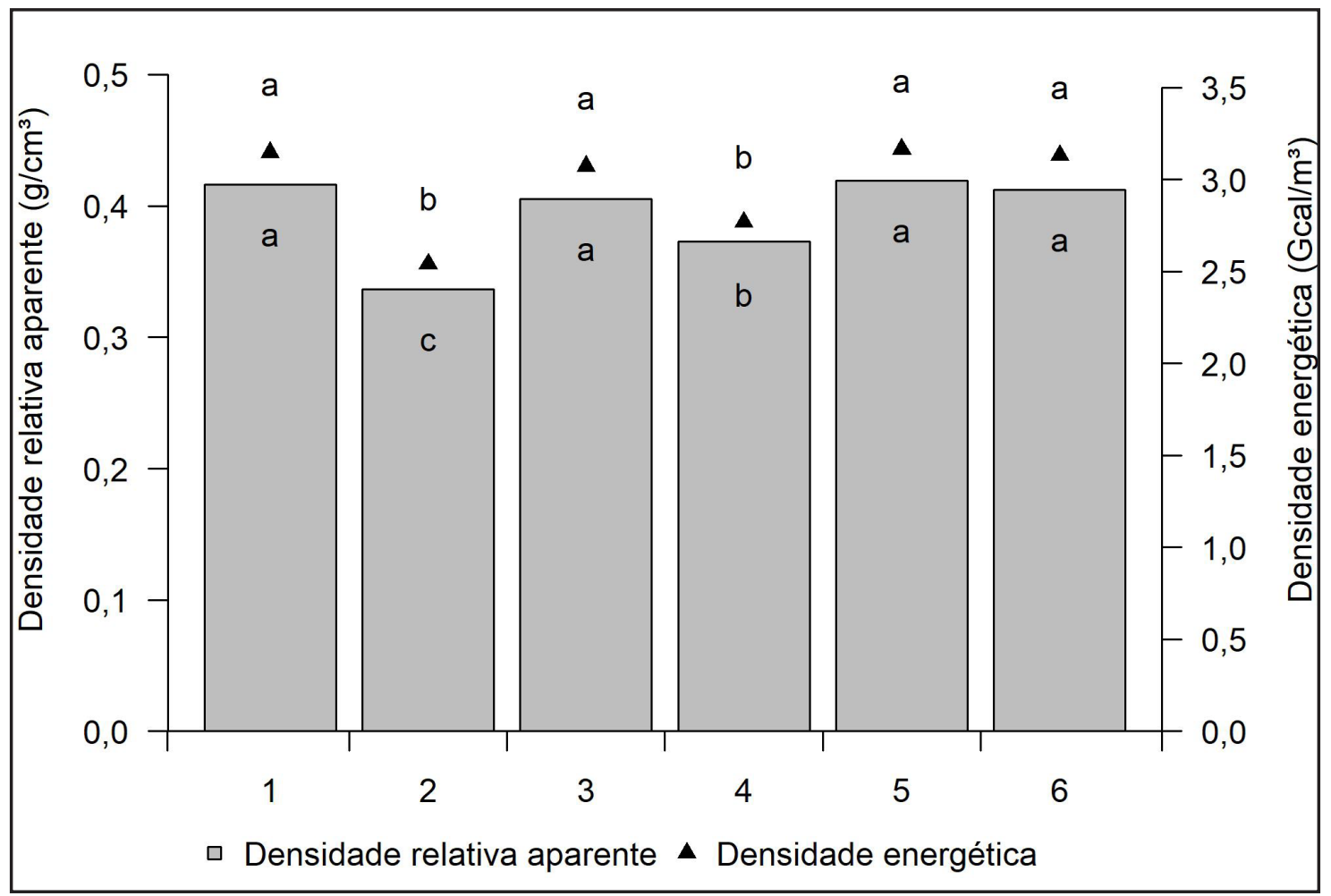

Fonte: Autores (2019)

Segundo Neves et al. (2011), é desejável madeira de elevada densidade básica, pois produzirá carvão mais denso, para otimizar o processo de redução do minério de ferro nos altos fornos siderúrgicos, reduzir os custos com o transporte e o consumo 
específico do reator. Dentro desse contexto, não se recomenda o uso do biorredutor proveniente da madeira dos clones 2 e 4.

NaTabela 3, foi verificado que o consumo específico de madeira apresentou efeito significativo de clone, sendo que o clone 2 apresentou o maior consumo específico de madeira, diferindo, estatisticamente, dos demais. Quanto maior o consumo específico de madeira $\left(\mathrm{m}^{3}\right)$ para produzir uma tonelada de carvão, menos eficiente é o material genético e maior será o custo de produção do biorredutor.

Tabela 3 - Valores médios das estimativas de consumo específico de madeira e eficiência energética da carbonização

\begin{tabular}{|c|c|c|c|}
\hline Clones & Cruzamento & CE $\left(m^{3} t^{-1}\right)$ & EE $(\%)^{\text {ns }}$ \\
\hline 1 & $\begin{array}{l}\text { Corymbia citriodora } \mathrm{x} \\
\text { Corymbia torelliana }\end{array}$ & $5,12^{(0,16)} \mathrm{C}$ & $53,05^{(0,57)} \mathrm{a}$ \\
\hline 2 & $\begin{array}{l}\text { Corymbia citriodora } \mathrm{x} \\
\text { Corymbia torelliana }\end{array}$ & $6,34^{(0,33)} \mathrm{a}$ & $52,63^{(1,10)} \mathrm{a}$ \\
\hline 3 & $\begin{array}{c}\text { Corymbia citriodora } \mathrm{x} \\
\text { Corymbia torelliana }\end{array}$ & $5,70^{(0,37)} \mathrm{b}$ & $53,25^{(0,69)} \mathrm{a}$ \\
\hline 4 & $\begin{array}{l}\text { Corymbia torelliana } \mathrm{x} \\
\text { Corymbia citriodora }\end{array}$ & $5,62^{(0,27)} \mathrm{b}$ & $54,08^{(1,44)} \mathrm{a}$ \\
\hline 5 & $\begin{array}{l}\text { Corymbia torelliana } \mathrm{x} \\
\text { Corymbia citriodora }\end{array}$ & $4,80^{(0,06)} \mathrm{C}$ & $54,01^{(0,97)} \mathrm{a}$ \\
\hline \multirow[t]{5}{*}{6} & $\begin{array}{l}\text { Corymbia torelliana } \mathrm{x} \\
\text { Corymbia citriodora }\end{array}$ & $5,24^{(0,17)} \mathrm{C}$ & $53,48^{(1,04)} \mathrm{a}$ \\
\hline & $\begin{array}{c}\text { Média Corymbia citriodora } \mathrm{x} \\
\text { Corymbia torelliana }\end{array}$ & 5,72 & 52,98 \\
\hline & $\begin{array}{c}\text { Média Corymbia torelliana } \mathrm{x} \\
\text { Corymbia citriodora }\end{array}$ & 5,22 & 53,86 \\
\hline & Média Geral & 5,47 & 53,42 \\
\hline & CVe (\%) & 6,44 & 2,50 \\
\hline
\end{tabular}

Fonte: Autores (2019)

Em que: $C E$ = consumo específico de madeira; $E E$ = eficiência energética da carbonização; $C V e$ = coeficiente de variação experimental. Valores médios seguidos da mesma letra não diferem entre si, a 5\% de probabilidade, pelo teste Scott-Knott.

A eficiência energética da carbonização não apresentou efeito significativo de clone. Esse resultado está relacionado ao efeito não significativo de clone tanto para o poder calorífico superior quanto para o rendimento gravimétrico em carvão vegetal. 
Deve ser ressaltado que há variação da eficiência energética com a temperatura máxima de carbonização, reduzindo com o aumento da temperatura até $700^{\circ} \mathrm{C} \mathrm{e}$ estabiliza, aproximadamente, em 34\% nas temperaturas mais elevadas (KWON et al., 2014).

Pela análise multivariada de componentes principais verifica-se que os dois primeiros componentes principais explicam 71,10\% da variância total associada aos dados (Tabela 4). Esse fato indica a alta correlação entre as variáveis e que as informações de maior relevância estão concentradas nesses dois componentes.

Tabela 4 - Autovetores, correlações e contribuição dos parâmetros originais nas duas componentes principais

\begin{tabular}{|c|c|c|c|c|c|c|}
\hline \multirow{2}{*}{ Variáveis originais } & \multicolumn{3}{|c|}{ Componente principal 1} & \multicolumn{3}{|c|}{ Componente principal 2} \\
\hline & $\hat{\mathbf{e}}_{1}$ & $\mathbf{r}$ & CONT & $\hat{\mathbf{e}}_{2}$ & $\mathbf{r}$ & CONT \\
\hline RGC & 0,263 & 0,561 & 6,94 & $-0,379$ & $-0,759$ & 14,40 \\
\hline RLP & $-0,391$ & $-0,832$ & 15,29 & $-0,132$ & $-0,264$ & 1,74 \\
\hline RGNC & 0,329 & 0,700 & 10,80 & 0,239 & 0,479 & 5,73 \\
\hline MV & 0,150 & 0,319 & 2,24 & $-0,270$ & $-0,540$ & 7,30 \\
\hline $\mathrm{CF}$ & $-0,168$ & $-0,357$ & 2,81 & $-0,330$ & 0,660 & 10,88 \\
\hline$C Z$ & 0,114 & 0,243 & 1,30 & $-0,381$ & $-0,761$ & 14,49 \\
\hline RCF & 0,279 & 0,594 & 7,79 & 0,304 & 0,608 & 9,26 \\
\hline DRA & 0,377 & 0,803 & 14,21 & 0,238 & 0,475 & 5,65 \\
\hline PCS & $-0,045$ & $-0,096$ & 0,20 & 0,451 & 0,901 & 20,31 \\
\hline DE & 0,240 & 0,512 & 5,78 & 0,019 & 0,038 & 0,04 \\
\hline EE & 0,351 & 0,747 & 12,30 & $-0,296$ & $-0,592$ & 8,77 \\
\hline $\mathrm{CE}$ & $-0,451$ & $-0,960$ & 20,33 & $-0,120$ & $-0,239$ & 1,43 \\
\hline Variância explicada (\%) & & 37,77 & & & 33,33 & \\
\hline Variância acumulada (\%) & & 37,77 & & & 71,10 & \\
\hline Autovetores & & 4,53 & & & 4,00 & \\
\hline
\end{tabular}

Fonte: Autores (2019)

Em que: Cont. = Contribuição; $\hat{e}_{1}=$ Autovetores; $r=$ correlação (valor mínimo considerado de 0,60); Valores em negrito apresentam valores superiores a 8,33\% (valor se a contribuição fosse uniforme).

A componente principal 1 encontra-se altamente correlacionada, positivamente, com o rendimento em gases não condensáveis, densidade relativa aparente e eficiência energética e, negativamente, com o rendimento em líquido pirolenhoso e consumo 
específico de madeira. Quanto maiores forem os escores dessa componente principal, mais propício será o clone de Corymbia para a produção de carvão, pois maior será a sua eficiência energética, para um menor consumo específico de madeira na conversão.

A componente principal 2 está correlacionada, positivamente, com o teor de carbono fixo, rendimento em carbono fixo e poder calorífico superior e, negativamente, com o rendimento gravimétrico em carvão e teor de cinzas, sendo que as relações entre essas variáveis podem influenciar a qualidade do carvão e seleção dos materiais avaliados. Nesse componente, vale destacar a relevância da influência do teor de cinzas no poder calorífico, pois à medida que cresce o teor de minerais, diminui o poder calorífico do carvão.Quanto maior o teor de carbono fixo, menor será o rendimento gravimétrico em carvão, porém maior será o rendimento em carbono fixo.

Esses resultados obtidos nas duas primeiras componentes principais reúnem características favoráveis e mais relevantes na seleção de clones de Corymbia sp. para a produção de carvão vegetal. Dias Júnior et al. (2015) também encontraram altas correlações em carvão de Eucalyptus sp. produzido a $500{ }^{\circ} \mathrm{C}$ entre teor de carbono fixo, teor de materiais voláteis, poder calorífico superior, rendimento em carvão vegetal e rendimento em carbono fixo pela análise de componentes principais.

A representação gráfica de vetores normalizados da análise de componentes principais está mostrada na Figura 2. Observa-se a formação de um grupo com os clones 1 e 6 com base nos escores das componentes principais consideradas. As características mais relevantes para a formação desse grupo foram a densidade relativa aparente e rendimento em carbono fixo. Dessa forma, pode considerar que 0 carvão vegetal produzido com a madeira desses clones, de acordo com a análise das componentes principais, será o mais indicado para ser utilizado como agente de dupla função (biotermorredutor) na siderurgia.

A dispersão dos clones estudados em relação as duas primeiras componentes principais apresentaram distinção entre os materiais genéticos de Corymbia sp. avaliados. Os clones que mais se distinguiram dos demais foram o 4 (Corymbia 
torelliana x Corymbia citriodora), em decorrência de seu maior teor de cinzas, e o 2 (Corymbia citriodora x Corymbia torelliana), por apresentar maior consumo específico de madeira na produção de carvão, logo, não são indicados para o uso siderúrgico; haja vista, a importância dessas propriedades na produção e desempenho do carvão vegetal nos altos fornos.

Figura 2 - Dispersão dos clones de Corymbia e diagrama de ordenação dos autovetores das duas primeiras componentes principais obtidas para os parâmetros do carvão vegetal

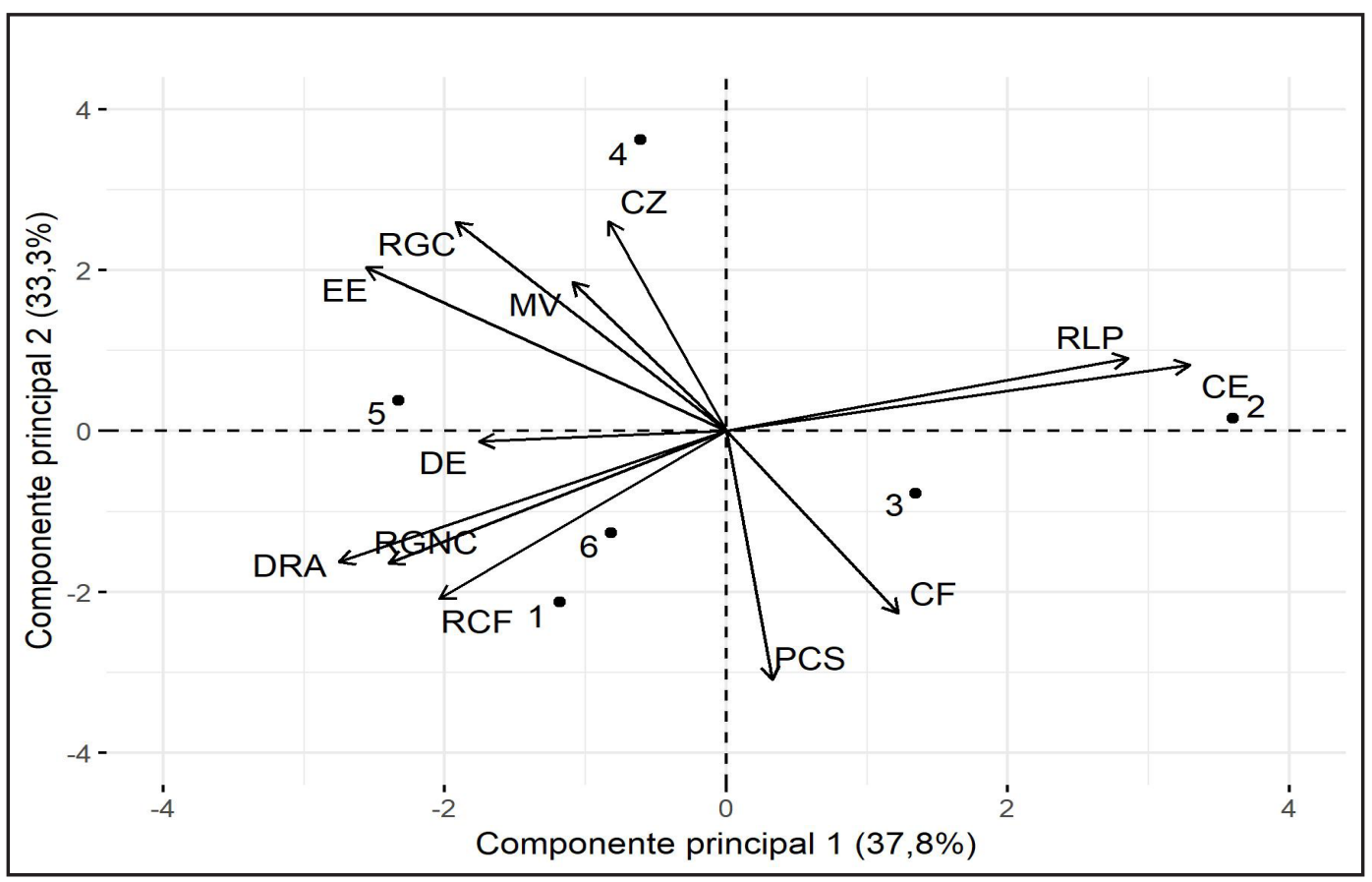

Fonte: Autores (2019)

\section{CONCLUSÃO}

O clone 1, clone híbrido do cruzamento Corymbia citriodora x Corymbia torelliana, foi o destaque para a produção de carvão vegetal e lenha, pois apresentou maiores densidades aparente e energética, maior teor e rendimento em carbono fixo, além de possuir menor consumo específico de madeira por tonelada de carvão vegetal produzido. 
Os clones 4 e 2 foram os que mais se distinguiram dos demais, respectivamente, em razão de seu maior teor de cinzas e por apresentar maior consumo específico de madeira na produção de carvão.

A geração de clones híbridos do cruzamento de Corymbia para a produção de carvão vegetal é uma boa alternativa pelo seu rápido crescimento e qualidades semelhantes de madeira e carvão vegetal a outras espécies, que já são usadas para a finalidade energética.

\section{AGRADECIMENTOS}

Os autores agradecem a CAPES pela concessão das bolsas de mestrado e doutorado ao primeiro autor e também às demais instituições de fomento (CNPq e FAPEMIG), e à empresa ArcelorMittal, pela parceria financeira e doação das árvores.

\section{REFERÊNCIAS}

AMERICAN SOCIETY FOR TESTING MATERIALS. D1762-84: Standard Test Method for Chemical Analysis of Wood Charcoal. Philadelphia: ASTM, 2007. 2 p.

AMERICAN SOCIETY FOR TESTING MATERIALS. E71187: Standard Test Method for Gross Calorific Value of Refuse Derived Fuel by the Bomb Calorimeter. Philadelphia: ASTM, 2004. 8 p.

ASSIS, M. R. et al. Qualidade e rendimentos do carvão vegetal de um clone híbrido de Eucalyptus grandis x Eucalyptus urophylla. Pesquisa Florestal Brasileira, Colombo, v. 32, n. 71, p. 291-302, set. 2012.

ASSOCIAÇÃO BRASILEIRA DE NORMAS TÉCNICAS. NBR 11941: madeira: determinação da densidade básica. Rio de Janeiro: ABNT, 2003. 6 p.

BRAND, M. A.; MUÑIZ, G. B. I. Influência da época de colheita da biomassa florestal sob sua qualidade para a geração de energia. Scientia Forestalis, Piracicaba, v. 38, v. 88, p. 619-628, dez. 2010.

BRUZUAL, C. F. Assessment of $\mathrm{CO}_{2}$ mitigation potential, biomass use and plantation areas to sustain charcoal-ironmaking. Tecnologia em Metalurgia, Materiais e Mineração, São Paulo, v. 12, n. 4, p. 325-334, out/dez. 2015.

CARDOSO, M. T. et al. Construção de um sistema de queima de gases da carbonização para redução da emissão de poluentes. Cerne, Lavras, v. 16, p. 115-124, jul. 2010.

CASTRO, A. F. N. M. et al. Análise multivariada para seleção de clones de eucalipto destinados a produção de carvão vegetal. Pesquisa Agropecuária Brasileira, Brasília, v. 48, n. 6, p. 627635, jun. 2013. 
COUTO, A. M. et al. Multivariate analysis applied to evaluation of Eucalyptus clones for bioenergy production. Cerne, Lavras, v. 19, n. 4, p. 525-533, oct./dec. 2013.

DIAS JÚNIOR, A. F. et al. Potencial energético de sete materiais genéticos de Eucalyptus cultivados no Estado do Rio de Janeiro. Scientia Forestalis, Piracicaba, v. 43, n. 108, p. 833843, dez. 2015.

KWON, G. J. et al. Tailoring the characteristics of carbonized wood charcoal by using different heating rates. Journal of the Korean Physical Society, Seoul, v. 64, n. 10, p. 1474-1478, May 2014.

LEE, D. J. et al. Comparative performance of Corymbia hybrids and parental species in subtropical Queensland and implications for breeding and deployment. Silvae Genetica, Varsóvia, v. 58, n. 5-6, p. 202-212, dez. 2009.

LOUREIRO, B. A. et al. Selection of superior clones of Corymbia hybrids based on wood and charcoal properties. Maderas. Ciencia y Tecnología, Concepción, v. 21, n. 4, p. 619-630, Aug. 2019.

MOUTINHO, V. H. P. et al. Characterization and statistical correlation between charcoal's physical and mechanical properties of Eucalyptus and Corymbia clones. Ciência Florestal, Santa Maria, v. 27, n. 3, p. 1095-1103, jul./set. 2017.

NEVES, T. A. et al. Avaliação de clones de Eucalyptus em diferentes locais visando à produção de carvão vegetal. Pesquisa Florestal Brasileira, Colombo, v. 31, n. 68, p. 319-330, dez. 2011.

OLIVEIRA, A. C. et al. Otimização da produção do carvão vegetal por meio do controle de temperaturas de carbonização. Árvore, Viçosa, v. 37, n. 3, p. 557-566, maio/jun. 2013.

PAULA, L. E. D. R. et al. Characterization of residues from plant biomass for use in energy generation. Cerne, Lavras, v. 17, n. 2, p. 237-246, abr./jun. 2011.

PEREIRA, B. L. C. et al. Influence of chemical composition of Eucalyptus wood on gravimetric yield and charcoal properties. BioResources, Raleigh, v. 8, n. 3, p. 4574-4592, Jul. 2013.

PROTÁSIO, T. P. et al. Avaliação da qualidade do carvão vegetal de Qualea parviflora. Pesquisa Florestal Brasileira, Colombo, v. 31, n. 68, p. 295-307, dez. 2011.

PROTÁSIO, T. P. et al. Avaliação tecnológica do carvão vegetal da madeira de clones jovens de Eucalyptus grandis e Eucalyptus urophylla. Scientia Forestalis, Piracicaba,v. 43, n. 108, p. 801816,dez. 2015.

PROTÁSIO, T. P. et al. Potencial siderúrgico e energético do carvão vegetal de clones de Eucalyptus spp. aos 42 meses de idade. Pesquisa Florestal Brasileira, Colombo, v. 33, n. 74, p. 137-149, jun. 2013.

PROTÁSIO, T. P. et al. Qualidade da madeira e do carvão vegetal oriundos de floresta plantada em Minas Gerais. Pesquisa Florestal Brasileira, Colombo, v. 34, n. 78, p. 111-123, abr./jun. 2014. 
R CORE TEAM. R: A Language and Environment for Statistical Computing. Vienna: R Foundation for Statistical Computing, 2016. Disponível em: https://www.r-project.org/. Acesso em: 15 out. 2019.

REIS, C.A.F.et al. Corymbia torelliana: estado da arte de pesquisas no Brasil. Colombo: Embrapa Florestas, 2014. $48 \mathrm{p}$.

ROUSSET, P. et al. Pressure effect on the quality of eucalyptus wood charcoal for the steel industry: A statistical analysis approach. Fuel Processing Technology, Amsterdam, v. 92, n. 10, p. 1890-1897, Oct. 2011.

SOARES, V. C. et al. Correlações entre as propriedades da madeira e do carvão vegetal de híbridos de eucalipto. Árvore, Viçosa, v. 38, n. 3, p. 543-549, maio/jun. 2014.

TRUGILHO, P. F. et al. Efeito da idade e material genético no rendimento e qualidade do carvão vegetal de eucalipto. Ciência da Madeira, Pelotas, v. 6, n. 3, p. 202-216, nov. 2015.

VALE, A. T.; DIAS, I. S.; SANTANA, M. A. E. Relações entre propriedades químicas, físicas e energéticas da madeira de cinco espécies de cerrado. Ciência Florestal, Santa Maria, v. 20, n. 1, p.137-145, jan./mar. 2010.

ZANUNCIO, A. J. V. et al. Secagem ao ar livre da madeira para produção de carvão vegetal. Floresta e Ambiente, Seropédica, v. 21, n. 3, p. 401-408, maio 2014.

\section{Contribuição de Autoria}

\section{1 - Breno Assis Loureiro}

Engenheiro Florestal, Me.

https://orcid.org/0000-0002-2080-4765 •loureiro_breno@yahoo.com.br

Contribuição: Conceituação, Análise Formal, Visualização, Investigação, Escrita primeira redação

\section{2 - Maíra Reis de Assis}

Engenheira Florestal, Pós-Doc., Dra.

https://orcid.org/0000-0001-5223-8019•maira.rassis@gmail.com

Contribuição: Conceituação, Análise Formal, Investigação, Metodologia 


\section{3 - Isabel Cristina Nogueira Alves de Melo}

Engenheira Florestal, Pós-Doc., Dra.

https://orcid.org/0000-0001-8068-6425• isabelnogueiraalves@gmail.com

Contribuição: Conceituação, Análise Formal, Investigação, Metodologia

\section{4 - Ana Flávia Fernandes de Oliveira}

Engenheira Florestal

https://orcid.org/0000-0001-9560-9107•faifernandes@hotmail.com

Contribuição: Investigação, Metodologia

\section{5 - Paulo Fernando Trugilho}

Engenheiro Florestal, Pós-Doc., Dr., Professor

https://orcid.org/0000-0002-6230-5462•trugilho@ufla.br

Contribuição: Obtenção de financiamento, Recursos, Metodologia, Supervisão, Administração do projeto, Escrita - revisão e edição

\section{Como citar este artigo}

Loureiro, B. A.; Assis, M. R.; Melo, I. C. N. A.; Oliveira, A. F. F.; Trugilho, P. F. Rendimento gravimétrico da carbonização e caracterização qualitativa do carvão vegetal em clones de híbridos de Corymbia spp para uso industrial. Ciência Florestal, Santa Maria, v. 31, n. 1, p. 214-232, 2021. DOI 10.5902/1980509836120. Disponível em: https://doi.org/10.5902/1980509836120. Acesso em: xx mês abreviado 202x. 